\title{
The role of vitamin $D$ in reproductive dysfunction in women - a systematic review
}

\author{
Patrycja Skowrońska', Ewa Pastuszek ${ }^{1,2}$, Waldemar Kuczyński ${ }^{3,4}$, Mariusz Jaszczoł ${ }^{5}$, Paweł Kućc, \\ Grzegorz Jakiel ${ }^{6,7}$, Izabela Wocławek-Potocka ${ }^{8}$, Krzysztof Łukaszuk ${ }^{1,2,9}$ \\ ${ }^{1}$ Department of Obstetrics and Gynecological Nursing, Faculty of Health Sciences, Medical University of Gdansk, Poland \\ 2 INVICTA Fertility and Reproductive Center, Gdańsk, Poland \\ ${ }^{3}$ Centre for Reproductive Medicine KRIOBANK, Białystok, Poland \\ ${ }^{4}$ Medical University of Bialystok, Poland \\ ${ }^{5}$ Department of Chemical and Process Engineering Chemical Faculty, Gdansk University of Technology, Poland \\ ${ }^{6}$ INVICTA Fertility and Reproductive Center, Warszawa, Poland \\ ${ }^{7}$ First Department of Obstetrics and Gynaecology, Medical Center of Postgraduate Education, Warsaw, Poland \\ ${ }^{8}$ Institute of Animal Reproduction and Food Research of the Polish Academy of Sciences, Department of Reproductive \\ Immunology and Pathology, Olsztyn, Poland \\ ${ }^{9}$ Department of Gyneacological Endocrinology, Medical University of Warsaw, Warsaw, Poland
}

Skowrońska P, Pastuszek E, Kuczyński W, Jaszczoł M, Kuć P, Jakiel G, Wocławek-Potocka I, Łukaszuk K. The role of vitamin D in reproductive dysfunction in women - a systematic review. Ann Agric Environ Med. 2016; 23(4): 671-676. doi: 10.5604/12321966.1226865

\section{Abstract}

Vitamin $D$ is essential for the proper functioning of the human body. There is also evidence of its strong association with fertility problems in women. This review aims to evaluate the relationship between vitamin $D$ and diseases affecting women's fertility (polycystic ovarian syndrome (PCOS), uterine leiomyomas and endometriosis), and in vitro fertilization (IVF) outcome. A systematic review of the literature was conducted in Scopus and PubMed for relevant English language publications since 1989. Vitamin D influences the functioning of the reproductive system in women and has been associated with PCOS, uterine leiomyomas, endometriosis and in vitro fertilization (IVF) outcome. However, further studies on larger groups of patients are needed to establish what role vitamin D plays in the treatment of female infertility.

\section{- Key words}

vitamin D, PCOS, endometriosis, uterine leiomyomas, in vitro fertilization

\section{INTRODUCTION}

Vitamin D is a group of fat-soluble steroids responsible for enhancing intestinal absorption of calcium and phosphate, which is directly related to the maintenance of the normal structure and function of the skeletal system. Vitamin D deficiency is frequently seen together with diabetes, various forms of cancer, and autoimmune diseases [1].

There are two major forms of vitamin $\mathrm{D}$ that have fundamental importance: ergocalciferol (vitamin D2) and cholecalciferol (vitamin D3) [2]. Both can be produced under ultraviolet B radiation (290-315 $\mathrm{nm}$ ) and do not have any biological activity. Ergocalciferol is produced in plants from ergosterol (ergosta-5,7,22-trien-3 $\beta$-ol) while cholecalciferol is synthesized by the epidermis cell from 7-dehydrocholesterol (7-DHC) (Fig. 1, 2) [3]. All of the serum cholecalciferol and ergocalciferol are bound to vitamin D-binding protein (VDBP) and transported to the liver where enzymatic hydroxylation takes place at $\mathrm{C}-25$ leading to 25- hydroxyvitamin D (25- $(\mathrm{OH}) \mathrm{D})$ [2]. This reaction is catalyzed by the group of hydroxylases belonging to the cytochrome P450 (CYP27A1, CYP3A4 and CYP2R1) [4]. The complex of vitamin $25-(\mathrm{OH}) \mathrm{D}$ and VDBP is transported from the liver to the kidneys (and other tissues) where the active form of vitamin $\mathrm{D}-1 \alpha, 25-(\mathrm{OH})_{2} \mathrm{D}\left(1 \alpha, 25-(\mathrm{OH})_{2} \mathrm{D} 2\right.$ and $\left.1 \alpha, 25-(\mathrm{OH})_{2} \mathrm{D} 3\right)$ is formed due to the action of the

Address for correspondence: Patrycja Skowrońska, Department of Obstetrics and Gynecological Nursing, Faculty of Health Sciences, Medical University of Gdansk, Dębinki 7, 80-952, Gdańsk, Poland

E-mail: p.kulwikowska@gumed.edu.pl

Received: 10 November 2015; accepted: 20 September 2016 1a-hydroxylase (CYP27B1). Both biologically active forms have identical properties. The level of vitamin $\mathrm{D}$ in serum is best reflected by the concentration of $25(\mathrm{OH}) \mathrm{D}$, due to its longer half-life and predominant amount in serum $[1,3]$.

Most daily requirement for vitamin D3 is derived from biosynthesis in the skin. Many environmental factors affects

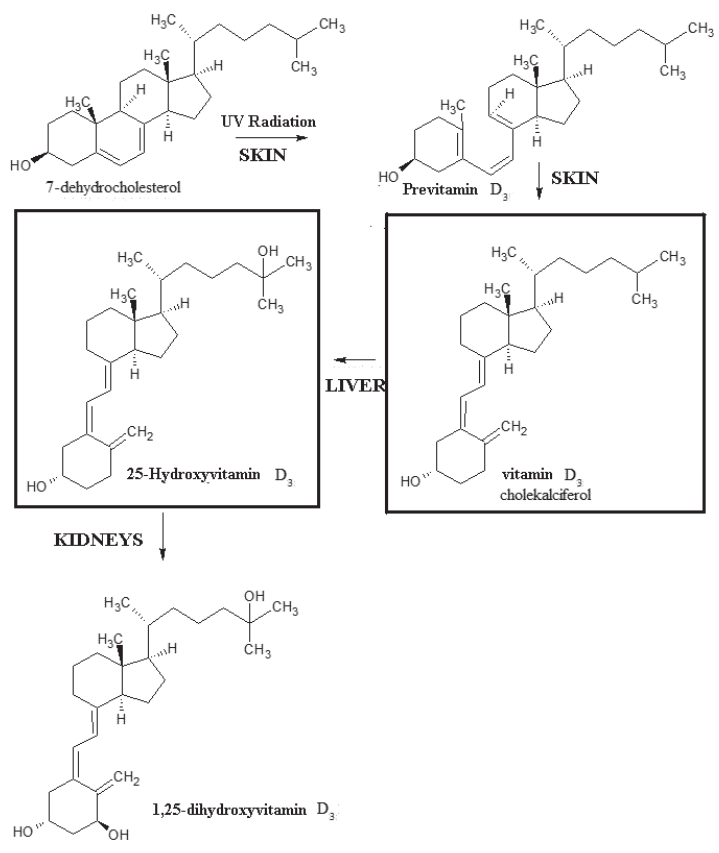

Figure 1. Synthesis of active form of vitamin D3 (frames: examples of forms determinable by LC-MS method) 


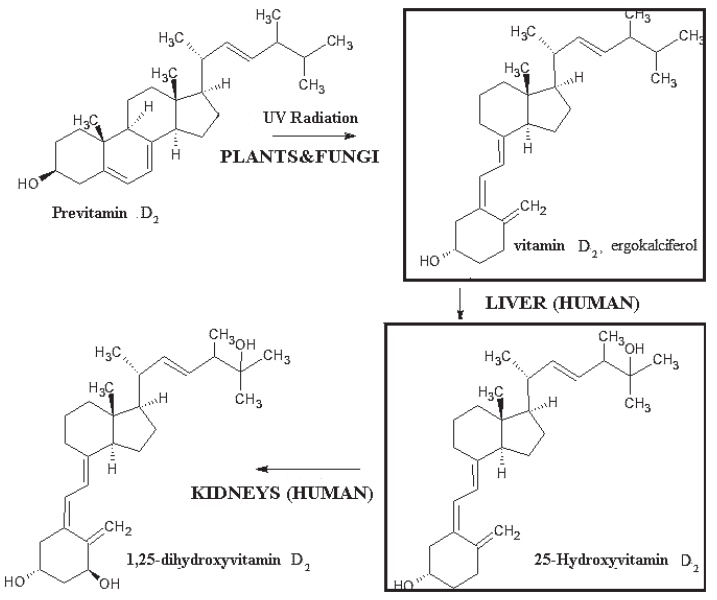

Figure 2. Synthesis of active forms of vitamin D2 (frames: examples of forms determinable by LC-MS method)

vitamin D skin production, such as: limited access to sunlight caused by latitude, season, cloudiness or air pollution. Skin condition and pigmentation (skin type) are also very important factors [2]. Skin production of vitamin D, largely dependent on environmental factors, is often insufficient to ensure meeting the daily recommended amount, especially in highly industrialized countries. The World Health Organization (WHO) defined 'vitamin D insufficiency' as serum level of $25 \mathrm{OHD}$ below $20 \mathrm{ng} / \mathrm{ml}$ (50 nmol/L) [5]. However, according to the Endocrine Society Clinical Practice Guideline, 'vitamin D deficiency' is defined as $25(\mathrm{OH}) \mathrm{D}$ below $20 \mathrm{ng} / \mathrm{ml}(50 \mathrm{nmol} / \mathrm{L})$, and 'vitamin D insufficiency' as $25(\mathrm{OH}) \mathrm{D}$ of $21-29 \mathrm{ng} / \mathrm{ml}(52,5-72,5 \mathrm{nmol} / \mathrm{L})$. A sufficient level of vitamin D is a concentration higher than $30 \mathrm{ng} / \mathrm{ml}$
(75 nmol/L). The cut-off point of $30 \mathrm{ng} / \mathrm{ml}(75 \mathrm{nmol} / \mathrm{L})$ is associated with maximal suppression of the parathyroid hormone (PTH) and optimal calcium absorption [6].

Biological activity. The active metabolites of vitamin D have broad and diverse biological functions. Active vitamin $\mathrm{D}$ is involved through genomic and non-genomic actions. In many tissues, vitamin $\mathrm{D}$ binds to the nuclear vitamin $\mathrm{D}$ receptor (VDR). The complex then binds to the receptor of 9-cis retinoic acid (RXR) to form a heterodimer with the properties of the transcription factor (genomic action) [7]. VDR controls more than 200 genes which are involved in metabolism, anabolism and resorption of the bones, mineral homeostasis, intestinal calcium transport, and cell cycle control [8]. VDR also influences the immune system by directly modulating T-cell proliferation [9] and activating the genes encoding the antimicrobial peptides with natural features of antibiotics [10]. VDR is also a repressor for interleukin reducing risk of some autoimmune diseases, such as diabetes mellitus (type 1) or rheumatoid arthritis $[3,11]$. Vitamin D and VDR also affects the reproductive system (Tab. 1).

This review aims to gather studies evaluating the relationship between vitamin $\mathrm{D}$ and diseases that affect women's fertility.

Physiological role of vitamin D in reproduction Endometriosis. Endometriosis is associated with endometrial hyperplasia outside the uterine cavity, occurring in $7-15 \%$ of menstruating women [12]. There are several hypotheses concerning the causes of endometriosis but the mechanisms of the disease are still unknown. The proposed mechanisms include the regression of endometrial cells into the body

Table 1. Effects of vitamin D on gynaecological disorders including methods used for its determination

\begin{tabular}{|c|c|c|c|}
\hline Disorder & Conclusion & Method & Ref. \\
\hline \multirow{4}{*}{ Endometriosis } & $\begin{array}{l}\text { Association of higher VDR (vitamin D receptor) and 1a-hydroxylase expression in } \\
\text { endometriosis }\end{array}$ & Immunohistochemistry method & [14] \\
\hline & $\begin{array}{l}\text { Association of the level of vitamin D with severity of endometriosis (serum } \\
25(\mathrm{OH}) \text { D3 levels - lower in women with severe endometriosis } 1 a, 25- \\
(\mathrm{OH})_{2} \text { D3levels - no difference) }\end{array}$ & radioimmunoassay & [17] \\
\hline & Association of high $1 \mathrm{a}, 25-(\mathrm{OH})_{2} \mathrm{D} 3$ level with endometriosis & radioimmunoassay & [18] \\
\hline & $\begin{array}{l}\text { Association of VDBP (vitamin D-binding protein) polymorphisms (GC*2) with } \\
\text { endometriosis }\end{array}$ & $\begin{array}{l}\text { two-dimensional difference gel } \\
\text { electrophoresis }\end{array}$ & [21] \\
\hline \multirow{4}{*}{$\begin{array}{l}\text { Symptoms of } \\
\text { Polycystic ovary } \\
\text { syndrome }\end{array}$} & Association of low level of vitamin D and insulin resistance & ELISA method, LC-MS, radioimmunoassay & {$[31,32,33]$} \\
\hline & Association of low level of vitamin D and obesity & radioimmunoassay & {$[39,40,41]$} \\
\hline & Correlation between vitamin D and hormone-binding globulin (SHGB) & ELISA method, radioimmunoassay & {$[31,39]$} \\
\hline & Correlation between vitamin $\mathrm{D}$ and the free androgen index (FAl) & radioimmunoassay & [39] \\
\hline \multirow{3}{*}{$\begin{array}{l}\text { Uterine } \\
\text { leiomyomas }\end{array}$} & Vitamin D inhibits growth and induces apoptosis of leiomyoma cells & $\begin{array}{l}\text { Molecular biology technique, } \\
\text { Immunohistochemistry method }\end{array}$ & {$[51,52]$} \\
\hline & $\begin{array}{l}\text { Association of low serum vitamin } D \text { and the increased risk of having } \\
\text { symptomatic uterine leiomyomas }\end{array}$ & $\begin{array}{l}\text { chemiluminescence technology, } \\
\text { radioimmunoassay }\end{array}$ & {$[55,59,60]$} \\
\hline & Association of $25(\mathrm{OH}) \mathrm{D} 3$ with uterine fibroid volume (inverse correlation) & radioimmunoassay & {$[60]$} \\
\hline \multirow[b]{2}{*}{$\begin{array}{l}\text { In vitro } \\
\text { fertilization }\end{array}$} & Association of high clinical pregnancy rate with high $25(\mathrm{OH}) \mathrm{D}$ concentrations & Immunoassay technique, radioimmunoassay & {$[68,69,70,71,72]$} \\
\hline & $\begin{array}{l}\text { Association of high follicular fluid vitamin D concentrations with low mean score } \\
\text { of embryo quality }\end{array}$ & electrochemiluminescence immunoassay & [78] \\
\hline
\end{tabular}


cavity (retrograde menstruation), genetic predisposition, immune disorders, cell metaplasia transport through the lymphatic and blood vessels, environmental factors, and action of vitamin D [13].

Studies by Agic et al. showed significantly higher VDR and $1 \alpha$-hydroxylase expression in endometriosis specimen than in healthy tissues, but without any statistically significant difference in the level of 25(OH)D3 [14]. However, a more recent study showed that genetic polymorphism of VDR was not an important factor in the pathogenesis of endometriosis (in Brazilian women) [15].

Data presented by Somigliana et al. showed that women suffering from endometriosis had increased serum level of $25(\mathrm{OH}) \mathrm{D} 3$, compared to the control group, and this difference was statistically significant. Concentration of $1 \alpha, 25-(\mathrm{OH})_{2} \mathrm{D} 3$ was also higher in the endometriosis group but the difference was not statistically significant. The quantitative detection of 25(OH)D3 level was performed using chemiluminescence technology, and 1a,25-(OH) $)_{2} \mathrm{D}$ was measured by radioimmunoassay [16]. The statistical significance of vitamin D3 was confirmed by further research using radioimmunoassay to determinate the level of 1a,25$(\mathrm{OH})_{2} \mathrm{D} 3$ and $25(\mathrm{OH}) \mathrm{D} 3$. Furthermore, the level of vitamin $\mathrm{D}$ was found to be dependent on the degree of severity of endometriosis [17].

Contradictory findings were shown by Hartwell et al. who reported a significantly higher level of $1 \alpha, 25-(\mathrm{OH})_{2} \mathrm{D} 3$ in women with endometriosis, while the level of $25(\mathrm{OH}) \mathrm{D} 3$ was comparable in both groups. This study, however, was limited by having a smaller sample [18]. A larger study by Harris et al. showed an inverse association between predicted plasma levels of 25(OH)D3 and the risk of endometriosis [19].

According to Borkowski et al., the concentration of vitamin $\mathrm{D}$ binding protein (VDBP) in peritoneal fluid of women with endometriosis was lower than in healthy patients, while the tendency for VDBP in serum was the opposite. These results were not statistically significant. Measurements of VDBP in plasma and peritoneal fluid of women with endometriosis and the control group were performed with ELISA method [20]. Another study attempting to determine the correlation between VDBP and endometriosis was performed by Faserl et al. [21]. They concluded that the concentration of vitamin D-binding protein was higher in all endometriosis patients compared with the control group $(\mathrm{P}<0.02)$. The authors suggested the possible involvement of polymorphism in the VDBP (GC-2) in the pathogenesis of endometriosis. Moreover, Faserl et al. speculated that the inability to sufficiently activate macrophages' phagocytotic function in subjects carrying the GC-2 polymorphism (more prevalent in endometriosis patients) may allow endometriotic tissues to implant in the peritoneal cavity [21].

Biologic mechanisms linking endometriosis and infertility include distorted pelvic anatomy, altered peritoneal function, ovulatory abnormalities, and impaired implantation [22]. The last mechanism could be related to the fact that the eutopic endometrium has reduced expression of biological markers of endometrial receptivity, such as $\alpha v \beta 3$ integrin, glycodelin A, osteopontin, and HOXA10 [23, 24]. 1,25(OH) 23 has a role in implantation likely involving the direct transcriptional activation of HOXA10 gene, which is involved in the implantation process as a potent $\alpha v \beta 3$ stimulator and might be a mediate trophoblastendometrial interactions during the implantation process [24].
$1,25(\mathrm{OH})_{2} \mathrm{D} 3$ promotes the shift away from Th1-type responses and favours Th2-type immunity by inhibiting the secretion of IL-12, IL-2, TNF and interferons by T cells, macrophages, and dendritic cells $[25,26]$.

In conclusion, concentrations of various forms of vitamin D and VDBP may become promising markers for endometriosis, but their possible dependence on environmental factors, such as time of year and type of skin, should also be taken into consideration.

Polycystic ovary syndrome. PCOS is the most common endocrine disorder causing infertility and affecting $5-10 \%$ of reproductive age women [27]. The causes of this disorder are unknown, but it has been shown that insulin resistance and obesity are related to PCOS [28].

Vitamin D impacts metabolism by affecting insulin secretion $[3,29,30]$. Therefore, the search for an association between PCOS and vitamin D metabolism appears to be justified.

A large number of observational studies have shown an association between a low level of $25(\mathrm{OH}) \mathrm{D} 3$ and insulin resistance [31, 32, 33]. However, the mechanisms remains unknown.

One theory relies on the regulatory effect of vitamin D on the intracellular and extracellular calcium level that is essential for insulin-mediated intracellular processes, and may have impact on insulin secretion $[34,35,36]$. Another hypothesis involves the stimulatory effect of vitamin $\mathrm{D}$ on the expression of insulin receptors leading to the increase of insulin sensitivity $[36,37]$. Finally, vitamin D influences the immune system and can cause a higher inflammatory response associated with insulin resistance [36, 38, 39].

Moreover, the association between concentration of vitamin $\mathrm{D}$ and obesity has also been demonstrated in women suffering from PCOS $[39,40,41]$. This can be a consequence of the association between obesity and insulin resistance, correlated with decreased levels of vitamin D [36, 39, 42, 43]. On the other hand, low levels of vitamin D in obesity patients can be caused by unwillingness of the women to expose their bodies to the sun [36].

Vitamin D deficiency is also related to an imbalance in hyperandrogenism markers, such as serum dehydroepiandrosterone (DHEAS), total testosterone (T), free androgen index (FAI), free testosterone, and sex hormone-binding globulin (SHBG) [31, 39, 44, 45, 46].

Hahn et al. examined a group of 120 women suffering from PCOS and observed a significant correlation between $25(\mathrm{OH}) \mathrm{D}$ (measured by radioimmunoassay method) and SHBG as well as FAI [39]. However, Wehr et al. examined a group of 206 women with PCOS and measured the levels of vitamin $25(\mathrm{OH}) \mathrm{D}$ in serum using ELISA method. The study documented a positive correlation of $25(\mathrm{OH}) \mathrm{D}$ with SHBG. Neither FAI, T, nor free testosterone showed such positive correlation [31]. In a pilot study by Pal at al., 12 overweight women with PCOS and vitamin D deficiency were supplemented with high doses of this vitamin and calcium. After 3 months, the patients' levels of total testosterone and androstenedione were reduced. However, SHBG and FAI and parameters of insulin resistance remained unchanged [42]. Other reports suggest that dietary supplementation with vitamin $\mathrm{D}$ or its analog improve insulin sensitivity and secretion [47] and the parameters of ovarian folliculogenesis and ovulation [48]. In conclusion, the association of vitamin 
D concentration with metabolic and endocrine parameters in PCOS women makes it a potential marker for that disease or a potential drug for metabolic disturbances in women with PCOS [46].

Uterine leiomyomas. Uterine leiomyomas are benign tumours of unknown etiology. These types of changes may occur due to the transformation of the uterine muscle under certain physiological and pathological conditions [49]. This disease affects mostly women during reproductive age [50]. Leiomyomas are often asymptomatic, therefore the number of women suffering from this disease is underestimated. The most common clinical symptoms include: excessive menstrual bleeding, dysmenorrhoea and intermenstrual bleeding, chronic pelvic pain, and possible impact on reproductive capacity (i.e. subfertility, early pregnancy loss, and later pregnancy complications) [49]. Vitamin D deficiency is currently thought to be a possible cause of this disease.

One of the first studies on cultured human leiomyoma cells demonstrated that vitamin $\mathrm{D}$ inhibited growth and induced apoptosis of these cells $[51,52]$. These conclusions were also confirmed in studies on animal model [53]. There was a strong correlation between low serum levels of vitamin D and having symptomatic uterine leiomyomas $[54,55]$. Studies show that uterine leiomyomas are more frequent in Afro-American women than in Caucasian and Hispanic populations $[49,56$, 57]. A possible explanation for such disparity in the statistical significance may be the naturally lower level of vitamin D in dark-skinned patients due to the inefficient synthesis of this vitamin under UV radiation [58].

Baird et al. compared odds of fibroids for women with sufficient and insufficient $25(\mathrm{OH}) \mathrm{D}$ levels and found that the former group had $32 \%$ lower odds compared with the latter. In their study, vitamin D levels were measured by radioimmunoassay. It is interesting to note that the association was similar for black and white women with no evidence of heterogeneity by ethnicity [59]. Sabry et al. also confirmed the association between $25(\mathrm{OH}) \mathrm{D}$ deficiency (measured by radioimmunoassay) and occurrence of uterine leiomyomas in both ethnic groups. Moreover, they observed statistically significant inverse correlation between the level of vitamin D and total fibroids mass volume [60]. However, within the ethnic groups this correlation was statistically significant only in black patients $[60,61]$. On the other hand, a study by Mitro et al. showed no relationship between $25(\mathrm{OH})$ $\mathrm{D}$ and odds of uterine fibroids among all examined women. However, probabilistic sensitivity analysis performed on the same data suggested that insufficient serum $25(\mathrm{OH})$ $\mathrm{D}$ was associated with significantly higher odds of uterine leiomyomas in white, but not in black patients [62].

The molecular mechanism of vitamin $\mathrm{D}$ action on leiomyoma was associated with a significant reduction in the effects of transforming growth factor beta 3 (TGF- $\beta 3$ ) induced protein expression of collagen type 1, fibronectin, and plasminogen activator inhibitor- 1 proteins, and the phosphorylation of Smad2, as well as nuclear translocation of Smad 2 and Smad3 [60].

The growth of uterine fibroids takes place due to the increase in cell proliferation and deposition of the extracellular matrix (ECM) [63]. Uterine fibroids contain abnormal deposition of extracellular matrix (ECM) components that play an important role in pathogenesis $[64,65,66]$. Halder et al. demonstrated that $1,25(\mathrm{OH})_{2} \mathrm{D} 3$ was able to reduce uterine fibroid growth by modulating the expression and activity of metalloproteinses (MMP-2 and MMP-9), which are involved in degradation of the ECM. Therefore, it seems that disturbances in degradation of ECM, could be an important prerequisite for the development of the fibroids [67].

The consistent data on the effects of vitamin D on uterine leiomyomas makes it a reasonable marker of this disease and potential therapeutic agent for the nonsurgical management of uterine fibroids.

In vitro fertilization (IVF) outcomes. Positive effects of vitamin $\mathrm{D}$ on the effectiveness of IVF treatment have not been clearly detected. Ozkan et al. in a study on a group of 84 patients found positive correlation between the level of vitamin D in serum and follicular fluid and tendency to achieve clinical pregnancy (CP) following IVF (increased likelihood of achieving CP by $6 \%, \mathrm{p}=0.030$ ). Moreover, high vitamin D level was significantly associated with the improved parameters of the controlled ovarian hyperstimulation [68]. Similar correlation between the level of vitamin D in serum and tendency to achieve CP following IVF was observed by Garbedian et al. [69] and Polyzos et al. [70]. This association was also demonstrated in the recipients of egg donation [71]. An interesting result was shown by Rudick et al. who observed that the status of vitamin D (in the serum and follicular fluid) and the achievement of CP is dependent on patient's ethnicity $(\mathrm{p}<0.01)$. Vitamin $\mathrm{D}$ deficiency was associated with lower pregnancy rates in non-Hispanic whites, but not in Asians [72].

However, other studies found that vitamin D deficiency did not play an important role in the outcome of ART [73, $74,75,76,77]$. Unfortunately, there is only a small amount of data showing the effects of vitamin $\mathrm{D}$ on the quality of embryos. Anifandis et al. showed a negative effect of vitamin $\mathrm{D}$ on the quality of embryos $(\mathrm{r}=-0.27, \mathrm{p}=0.027)$. They reported a lower quality of embryos and lower likelihood to achieve $\mathrm{CP}$ in women who had a sufficient vitamin D status $(25(\mathrm{OH})$ $\mathrm{D}>30 \mathrm{ng} / \mathrm{ml}$ in follicular fluid), in comparison with women with insufficient (follicular fluid 25(OH)D 20.1-30ng/ml) or deficient vitamin D status (follicular fluid $25(\mathrm{OH}) \mathrm{D}$ $<20 \mathrm{ng} / \mathrm{ml}$ ) [36, 78]. However, Rudick et al. did not observe correlation between vitamin D deficiency and ovarian stimulation parameters nor embryo quality, suggesting its effect may be mediated through the endometrium [72].

Given such contradictory results, there is a need for further research using reference methods for direct determination of the level of vitamin $\mathrm{D}$.

\section{CONCLUSIONS}

Vitamin D is involved in regulating the functions of the female reproductive system. Vitamin D status has been associated with PCOS, endometriosis, uterine leiomyomas, and in vitro fertilization (IVF) outcome. However further studies using reference methods for direct determination of the level of vitamin D are needed to confirm its role in the treatment of female infertility. 


\section{REFERENCES}

1. Holick MF. Vitamin D deficiency. N Engl J Med. 2007; 357(3): 266-81

2. Webb AR. Who, what, where and when-influences on cutaneous vitamin D synthesis. Prog Biophys Mol Biol. 2006; 92(1): 17-25.

3. Anagnostis P, Karras S, Goulis DG. Vitamin D in human reproduction: a narrative review. Int J Clin Pract. 2013; 67(3): 225-35.

4. Prosser DE, Jones G. Enzymes involved in the activation and inactivation of vitamin D. Trends Biochem Sci. 2004; 29(12): 664-73.

5. Prevention and management of osteoporosis. World Health Organ Tech Rep Ser. 2003; 921: 1-164, back cover.

6. Holick MF, Binkley NC, Bischoff-Ferrari HA, Gordon CM, Hanley DA, Heaney RP, et al. Evaluation, treatment, and prevention of vitamin D deficiency: an Endocrine Society clinical practice guideline. J Clin Endocrinol Metab. 2011; 96(7): 1911-30.

7. Bikle D. Vitamin D: Production, Metabolism, and Mechanisms of Action. In: De Groot LJ, Beck-Peccoz P, Chrousos G, Dungan K, Grossman A, Hershman JM, et al., editors. Endotext [Internet]. South Dartmouth (MA): MDText.com, Inc.; 2000 [cited 2016 Jul 23]. Available from: http://www.ncbi.nlm.nih.gov/books/NBK278935/

8. Haussler MR, Jurutka PW, Mizwicki M, Norman AW. Vitamin D receptor (VDR)-mediated actions of $1 \alpha, 25(\mathrm{OH})_{2}$ vitamin $\mathrm{D}_{3}$ : genomic and non-genomic mechanisms. Best Pract Res Clin Endocrinol Metab. 2011; 25(4): 543-59.

9. Gombart AF. The vitamin D-antimicrobial peptide pathway and its role in protection against infection. Future Microbiology. 2009; 4(9): $1151-65$

10. Wang T-T, Nestel FP, Bourdeau V, Nagai Y, Wang Q, Liao J, et al. Cutting edge: 1,25-dihydroxyvitamin D3 is a direct inducer of antimicrobial peptide gene expression. J Immunol. 2004; 173(5): 2909-12.

11. Nagpal S, Na S, Rathnachalam R. Noncalcemic actions of vitamin D receptor ligands. Endocr Rev. 2005; 26(5): 662-87.

12. Bręborowicz G. Położnictwo i ginekologia. Warszawa: Wydawnictwo Lekarskie PZWL; 2005 (in Polish).

13. Sayegh L, Fuleihan GE-H, Nassar AH. Vitamin D in endometriosis: a causative or confounding factor? Metab Clin Exp. 2014; 63(1): 32-41.

14. Agic A, Xu H, Altgassen C, Noack F, Wolfler MM, Diedrich K, et al. Relative expression of 1,25-dihydroxyvitamin D3 receptor, vitamin D 1 alpha-hydroxylase, vitamin D 24-hydroxylase, and vitamin D 25-hydroxylase in endometriosis and gynecologic cancers. Reprod Sci. 2007; 14(5): 486-97.

15. Vilarino FL, Bianco B, Lerner TG, Teles JS, Mafra FA, Christofolini DM, et al. Analysis of vitamin D receptor gene polymorphisms in women with and without endometriosis. Hum Immunol. 2011; 72(4): 359-63.

16. Somigliana E, Panina-Bordignon P, Murone S, Di Lucia P, Vercellini P, Vigano P. Vitamin D reserve is higher in women with endometriosis. Hum Reprod. 2007; 22(8): 2273-8.

17. Miyashita M, Koga K, Izumi G, Sue F, Makabe T, Taguchi A, et al. Effects of 1,25-Dihydroxy Vitamin $\mathrm{D}_{3}$ on Endometriosis. The Journal of Clinical Endocrinology \& Metabolism. 2016; 101(6): 2371-9.

18. Hartwell D, Rødbro P, Jensen SB, Thomsen K, Christiansen C. Vitamin $\mathrm{D}$ metabolites--relation to age, menopause and endometriosis. Scand J Clin Lab Invest. 1990; 50(2): 115-21.

19. Harris HR, Chavarro JE, Malspeis S, Willett WC, Missmer SA. Dairyfood, calcium, magnesium, and vitamin D intake and endometriosis: a prospective cohort study. Am J Epidemiol. 2013; 177(5): 420-30.

20. Borkowski J, Gmyrek GB, Madej JP, Nowacki W, Goluda M, Gabryś M, et al. Serum and peritoneal evaluation of vitamin D-binding protein in women with endometriosis. Postepy Hig Med Dosw (Online). 2008; 62: $103-9$.

21. Faserl K, Golderer G, Kremser L, Lindner H, Sarg B, Wildt L, et al. Polymorphism in vitamin D-binding protein as a genetic risk factor in the pathogenesis of endometriosis. J Clin Endocrinol Metab. 2011; 96(1): E233-241.

22. Practice Committee of the American Society for Reproductive Medicine. Endometriosis and infertility: a committee opinion. Fertil Steril. 2012; 98(3): 591-8.

23. Lessey BA, Castelbaum AJ, Sawin SW, Buck CA, Schinnar R, Bilker W, et al. Aberrant integrin expression in the endometrium of women with endometriosis. J Clin Endocrinol Metab. 1994; 79(2): 643-9.

24. Wei Q, St Clair JB, Fu T, Stratton P, Nieman LK. Reduced expression of biomarkers associated with the implantation window in women with endometriosis. Fertil Steril. 2009; 91(5): 1686-91.

25. Taylor HS, Bagot C, Kardana A, Olive D, Arici A. HOX gene expression is altered in the endometrium of women with endometriosis. Hum Reprod. 1999; 14(5): 1328-31.
26. D’Ambrosio D, Cippitelli M, Cocciolo MG, Mazzeo D, Di Lucia P, Lang $\mathrm{R}$, et al. Inhibition of IL-12 production by 1,25-dihydroxyvitamin D3. Involvement of NF-kappaB downregulation in transcriptional repression of the p40 gene. Journal of Clinical Investigation. 1998; 101(1): 252-62.

27. Diamanti-Kandarakis E, Kouli CR, Bergiele AT, Filandra FA, Tsianateli TC, Spina GG, et al. A survey of the polycystic ovary syndrome in the Greek island of Lesbos: hormonal and metabolic profile. J Clin Endocrinol Metab. 1999; 84(11): 4006-11.

28. Dunaif A. Insulin resistance and the polycystic ovary syndrome: mechanism and implications for pathogenesis. Endocr Rev. 1997; 18(6): 774-800.

29. Mitri J, Dawson-Hughes B, Hu FB, Pittas AG. Effects of vitamin D and calcium supplementation on pancreatic cell function, insulin sensitivity, and glycemia in adults at high risk of diabetes: the Calcium and Vitamin D for Diabetes Mellitus (CaDDM) randomized controlled trial. American Journal of Clinical Nutrition. 2011; 94(2): 486-94.

30. George PS, Pearson ER, Witham MD. Effect of vitamin D supplementation on glycaemic control and insulin resistance: a systematic review and meta-analysis. Diabet Med. 2012; 29(8): e142-150.

31. Wehr E, Pilz S, Schweighofer N, Giuliani A, Kopera D, Pieber TR, et al. Association of hypovitaminosis D with metabolic disturbances in polycystic ovary syndrome. Eur J Endocrinol. 2009; 161(4): 575-82.

32. Li HWR, Brereton RE, Anderson RA, Wallace AM, Ho CKM. Vitamin $\mathrm{D}$ deficiency is common and associated with metabolic risk factors in patients with polycystic ovary syndrome. Metab Clin Exp. 2011; 60(10): 1475-81.

33. Ngo DTM, Chan WP, Rajendran S, Heresztyn T, Amarasekera A, Sverdlov AL, et al. Determinants of insulin responsiveness in young women: Impact of polycystic ovarian syndrome, nitric oxide, and vitamin D. Nitric Oxide. 2011; 25(3): 326-30.

34. Pittas AG, Lau J, Hu FB, Dawson-Hughes B. The role of vitamin D and calcium in type 2 diabetes. A systematic review and meta-analysis. J Clin Endocrinol Metab. 2007; 92(6): 2017-29.

35. Milner RD, Hales CN. The role of calcium and magnesium in insulin secretion from rabbit pancreas studied in vitro. Diabetologia. 1967; 3(1): 47-9.

36. Lerchbaum E, Obermayer-Pietsch B. MECHANISMS IN ENDOCRINOLOGY: Vitamin D and fertility: a systematic review. European Journal of Endocrinology. 2012; 166(5): 765-78.

37. Maestro B, Molero S, Bajo S, Dávila N, Calle C. Transcriptional activation of the human insulin receptor gene by 1,25 -dihydroxyvitamin $\mathrm{D}(3)$. Cell Biochem Funct. 2002; 20(3): 227-32.

38. Shoelson SE, Herrero L, Naaz A. Obesity, inflammation, and insulin resistance. Gastroenterology. 2007; 132(6): 2169-80.

39. Hahn S, Haselhorst U, Tan S, Quadbeck B, Schmidt M, Roesler S, et al. Low serum 25-hydroxyvitamin D concentrations are associated with insulin resistance and obesity in women with polycystic ovary syndrome. Exp Clin Endocrinol Diabetes. 2006; 114(10): 577-83.

40. Mahmoudi T, Gourabi H, Ashrafi M, Yazdi RS, Ezabadi Z. Calciotropic hormones, insulin resistance, and the polycystic ovary syndrome. Fertil Steril. 2010; 93(4): 1208-14.

41. Panidis D, Balaris C, Farmakiotis D, Rousso D, Kourtis A, Balaris V, et al. Serum parathyroid hormone concentrations are increased in women with polycystic ovary syndrome. Clin Chem. 2005; 51(9): 1691-7.

42. Pal L, Berry A, Coraluzzi L, Kustan E, Danton C, Shaw J, et al. Therapeutic implications of vitamin D and calcium in overweight women with polycystic ovary syndrome. Gynecological Endocrinology. 2012; 28(12): 965-8.

43. Kamycheva E, Joakimsen RM, Jorde R. Intakes of calcium and vitamin $\mathrm{d}$ predict body mass index in the population of Northern Norway. J Nutr. 2003; 133(1): 102-6.

44. Merino PM, Codner E, Cassorla F. A rational approach to the diagnosis of polycystic ovarian syndrome during adolescence. Arquivos Brasileiros de Endocrinologia \& Metabologia. 2011; 55(8): 590-8.

45. Yildizhan R, Kurdoglu M, Adali E, Kolusari A, Yildizhan B, Sahin HG, et al. Serum 25-hydroxyvitamin D concentrations in obese and nonobese women with polycystic ovary syndrome. Arch Gynecol Obstet. 2009; 280(4): 559-63.

46. Shahrokhi SZ, Ghaffari F, Kazerouni F. Role of vitamin D in female Reproduction. Clinica Chimica Acta. 2016; 455: 33-8.

47. Kotsa K, Yavropoulou MP, Anastasiou O, Yovos JG. Role of vitamin D treatment in glucose metabolism in polycystic ovary syndrome. Fertil Steril. 2009; 92(3): 1053-8.

48. Irani M, Minkoff H, Seifer DB, Merhi Z. Vitamin D increases serum levels of the soluble receptor for advanced glycation end products in women with PCOS. J Clin Endocrinol Metab. 2014; 99(5): E886-890. 
49. Ciavattini A, Di Giuseppe J, Stortoni P, Montik N, Giannubilo SR, Litta P, et al. Uterine fibroids: pathogenesis and interactions with endometrium and endomyometrial junction. Obstet Gynecol Int. 2013; 2013: 173184 .

50. Laughlin SK, Schroeder JC, Baird DD. New directions in the epidemiology of uterine fibroids. Semin Reprod Med. 2010; 28(3): 204-17.

51. Sharan C, Halder SK, Thota C, Jaleel T, Nair S, Al-Hendy A. Vitamin D inhibits proliferation of human uterine leiomyoma cells via catecholO-methyltransferase. Fertil Steril. 2011; 95(1): 247-53.

52. Bläuer M, Rovio PH, Ylikomi T, Heinonen PK. Vitamin D inhibits myometrial and leiomyoma cell proliferation in vitro. Fertility and Sterility. 2009; 91(5): 1919-25.

53. Halder SK, Sharan C, Al-Hendy A. Vitamin D treatment induces dramatic shrinkage of uterine leiomyomas growth in the Eker rat model. Fertility and Sterility. 2010; 94(4): S75-S76.

54. Abdelraheem MS, Al-Hendy A. Serum vitamin D3 level inversely correlates with total fibroid tumor burden in women with symptomatic uterine fibroid. Fertility and Sterility. 2010; 94(4): S74.

55. Paffoni A, Somigliana E, Vigano' P, Benaglia L, Cardellicchio L, Pagliardini L, et al. Vitamin D Status in Women With Uterine Leiomyomas. The Journal of Clinical Endocrinology \& Metabolism. 2013; 98(8): E1374-E1378.

56. Marshall LM, Spiegelman D, Barbieri RL, Goldman MB, Manson JE, Colditz GA, et al. Variation in the incidence of uterine leiomyoma among premenopausal women by age and race. Obstet Gynecol. 1997; 90(6): 967-73.

57. Kjerulff KH, Langenberg P, Seidman JD, Stolley PD, Guzinski GM. Uterine leiomyomas. Racial differences in severity, symptoms and age at diagnosis. J Reprod Med. 1996; 41(7): 483-90.

58. Rostand SG. Vitamin D, blood pressure, and African Americans: toward a unifying hypothesis. Clin J Am Soc Nephrol. 2010; 5(9): 1697-703.

59. Baird DD, Hill MC, Schectman JM, Hollis BW. Vitamin d and the risk of uterine fibroids. Epidemiology. 2013; 24(3): 447-53.

60. Sabry M, Halder SK, Allah ASA, Roshdy E, Rajaratnam V, Al-Hendy A. Serum vitamin D3 level inversely correlates with uterine fibroid volume in different ethnic groups: a cross-sectional observational study. Int J Womens Health. 2013; 5: 93-100.

61. Sabry M, Al-Hendy A. Medical treatment of uterine leiomyoma. Reprod Sci. 2012; 19(4): 339-53.

62. Mitro SD, Zota AR. Vitamin D and uterine leiomyoma among a sample of US women: Findings from NHANES, 2001-2006. Reproductive Toxicology. 2015; 57: 81-6.

63. Walker CL, Stewart EA. Uterine fibroids: the elephant in the room. Science. 2005; 308(5728): 1589-92.

64. Stewart EA, Friedman AJ, Peck K, Nowak RA. Relative overexpression of collagen type I and collagen type III messenger ribonucleic acids by uterine leiomyomas during the proliferative phase of the menstrual cycle. J Clin Endocrinol Metab. 1994; 79(3): 900-6.
65. Sozen I, Arici A. Interactions of cytokines, growth factors, and the extracellular matrix in the cellular biology of uterine leiomyomata. Fertil Steril. 2002; 78(1): 1-12.

66. Malik M, Catherino WH. Novel method to characterize primary cultures of leiomyoma and myometrium with the use of confirmatory biomarker gene arrays. Fertil Steril. 2007; 87(5): 1166-72.

67. Halder SK, Osteen KG, Al-Hendy A. Vitamin D3 inhibits expression and activities of matrix metalloproteinase-2 and -9 in human uterine fibroid cells. Hum Reprod. 2013; 28(9): 2407-16.

68. Ozkan S, Jindal S, Greenseid K, Shu J, Zeitlian G, Hickmon C, et al. Replete vitamin D stores predict reproductive success following in vitro fertilization. Fertil Steril. 2010; 94(4): 1314-9.

69. Garbedian K, Boggild M, Moody J, Liu KE. Effect of vitamin D status on clinical pregnancy rates following in vitro fertilization. CMAJ Open. 2013; 1(2): E77-E82.

70. Polyzos NP, Anckaert E, Guzman L, Schiettecatte J, Van Landuyt L, Camus $\mathrm{M}$, et al. Vitamin D deficiency and pregnancy rates in women undergoing single embryo, blastocyst stage, transfer (SET) for IVF/ ICSI. Human Reproduction. 2014; 29(9): 2032-40.

71. Rudick BJ, Ingles SA, Chung K, Stanczyk FZ, Paulson RJ, Bendikson $\mathrm{KA}$. Influence of vitamin D levels on in vitro fertilization outcomes in donor-recipient cycles. Fertil Steril. 2014; 101(2): 447-52.

72. Rudick B, Ingles S, Chung K, Stanczyk F, Paulson R, Bendikson K. Characterizing the influence of vitamin D levels on IVF outcomes. Human Reproduction. 2012; 27(11): 3321-7.

73. Aleyasin A, Hosseini MA, Mahdavi A, Safdarian L, Fallahi P, Mohajeri MR, et al. Predictive value of the level of vitamin $\mathrm{D}$ in follicular fluid on the outcome of assisted reproductive technology. Eur J Obstet Gynecol Reprod Biol. 2011; 159(1): 132-7.

74. Franasiak JM, Molinaro TA, Dubell EK, Scott KL, Ruiz AR, Forman EJ, et al. Vitamin D levels do not affect IVF outcomes following the transfer of euploid blastocysts. American Journal of Obstetrics and Gynecology. 2015; 212(3): 315.e1-315.e6.

75. Firouzabadi RD, Rahmani E, Rahsepar M, Firouzabadi MM. Value of follicular fluid vitamin $\mathrm{D}$ in predicting the pregnancy rate in an IVF program. Arch Gynecol Obstet. 2014; 289(1): 201-6.

76. Lv SS, Wang JY, Wang XQ, Wang Y, Xu Y. Serum vitamin D status and in vitro fertilization outcomes: a systematic review and meta-analysis. Archives of Gynecology and Obstetrics. 2016; 293(6): 1339-45.

77. Van de Vijver A, Drakopoulos P, Van Landuyt L, Vaiarelli A, Blockeel C, Santos-Ribeiro S, et al. Vitamin D deficiency and pregnancy rates following frozen-thawed embryo transfer: a prospective cohort study. Human Reproduction. 2016; 31(8): 1749-54.

78. Anifandis GM, Dafopoulos K, Messini CI, Chalvatzas N, Liakos N, Pournaras S, et al. Prognostic value of follicular fluid 25-OH vitamin $\mathrm{D}$ and glucose levels in the IVF outcome. Reproductive Biology and Endocrinology. 2010; 8(1): 91. 